\title{
SPOROTRICHOSIS FOLLOWING MOUSE BITE WITH CERTAIN IMMUNOLOGIC DATA
}

\author{
Plate 4 \\ Josiah J. Moore and David Johe Davis \\ From the Department of Pathology and Bacteriology, University of Illinois, College of \\ Medicine, Chicago
}

Sporotrichosis occurs spontaneously in the horse, mule, dog, rat, and man. The life history and the mode of transmission of the sporotricha are not well known. The disease practically always follows an injury to the skin, usually a puncture wound or an abrasion on an extremity. Lutz and Splendore ${ }^{1}$ in Brazil observed the disease in rats and thought it was commonly transmitted from animal to animal through bites and scratches on the tail or extremities. A number of interesting cases have been reported following injuries received from the bites of lower animals. Recently the literature on the relation of animal and human sporotrichosis has been thoroughly reviewed by K. F. Meyer. ${ }^{2}$

Sutton $^{3}$ reported a case following a hen bite on the back of the hand. The wound later suppurated under home treatment. About 4 weeks later abscesses began to form on the forearm, no other part of the body being affected. Clinically this case was typical sporotrichosis but cultures evidently were not made. Microscopic examination of the contents of the abscesses revealed no organisms.

Olsen's ${ }^{4}$ case was one in which the primary lesion appeared on the dorsum of the hand. No reference is made to previous injury but the statement appears that the patient had handled and killed many gophers, some of which were afflicted with sores.

Jeanselme and Chevallier ${ }^{5}$ report an interesting case in a woman who developed nodular, gummatous sporotrichosis of the arm following the bite on the thumb by a white rat. This rat had been artificially inoculated with Sporotrichum jeanselme and was suffering from the experimental infection in various parts of the body. The nodules appeared on the arm nearly 3 months after the bite. The lesions were typical. The sporo-agglutination test was positive with Sporotrichum beurmanni at $1 / 300$. A strong local intracutaneous test was obtained and a marked general reaction followed the subcutaneous injection of the killed organisms. The fixation test was negative.

Received for publication March 25, 1918.

1 Centralbl. f. Bacteriol., I, O., 1917, 45, p. 631.

2 Jour. Am. Med. Assn., 1915, 65, p. 576.

s Ibid., 1910,55, p. 2213.

4 Ibid., 1912, 59, p. 941.

s Bull. et mém. Soc. méd. d. hôp. de Paris, 1911, 31, p. 287. 
Rispal and Dalous" report a case which is difficult to analyze. In 1877 the patient was operated on for phlegmon which followed the bite of a horse. It reappeared 10 years later and in 1909 there was still an old cicatrix. Here there developed multiple nodules which on examination proved to be an infection with Sporotrichum beurmanni.

de Beurmann and Gougerot ${ }^{T}$ reported a patient seen by Rouslacroix who was bitten on the finger by a small dog. In 4 or 5 days the finger became painful, slightly inflamed and swollen. In about a month the skin ulcerated and discharged pus. Twenty-seven days after the bite, the first nodules developed on the hand and arm. The organism isolated from the lesions was Sporotrichum beurmanni. Another case of Rouslacroix reported in 1913 by de Beurmann and Gougerot, was attributed to the bite of a parrot.

In none of these cases can it be stated with certainty that the sporotricha were actually carried into the lesion by the teeth or that they were present in the mouth of the animals at the time. They may have been on the skin of the patient or may have later found their way into the wound, the bite simply serving as an atrium as any other puncture wound might do.

The patient whom we had the opportunity of observing, a boy, aged 13, was bitten on the index finger of his left hand by a field mouse about Sept. 10, 1916. This occurred while he was spending his vacation near Belfield, N. D., on the Little Missouri River. He had caught the mouse in a flax field and while playing with it received the bite. The wound bled at the time but was apparently healed in a few days. About 2 weeks later he noticed a swelling of the finger at approximately the point of the old bite. This increased until the entire terminal phalanx was swollen, reddened and hard but not very painful. By October 13 it had "come to a head" and was opened with a needle. There was considerable discharge of yellow pus which continued for several days, later becoming more watery in consistency.

October 19 a painless nodule was discovered on the arm some distance above the wrist. Two days later he visited a physician who enlarged the opening on the finger, cleaned it with carbolic acid and applied a wet dressing. No improvement followed, the nodules continuing to increase in size and number and November 5 the patient consulted Dr. Yeakel of Chicago, who thinking the disease resembled blastomycosis, referred the patient to us for bacteriologic examination.

Cultures were made from the lesion on the finger November 6 and 8 . The material was obtained from the lesion by first removing the slough and scab and then passing a sterile platinum loop deep down to the base and under the margins of the ulcer. The granulations here were abundant and bled readily. Many leukocytes were present. Tubes of various mediums were inoculated and placed at both incubator and room temperature. After a few days all of the tubes yielded growths, several a pure culture of an organism suggestive of Sporotrichum schenckii. Transfers were made to various other mediums and several pure cultures of the organism were thus obtained.

November 11 a large nodule above the wrist was aspirated and cultures and smears were likewise made of the thick mucoid, honeylike pus obtained.

${ }^{6}$ Arch. de dermat. et de syph., 1909, 12, p. 689.

T Les Sporotrichoses, 1912, p. 278. 
No organisms could be found in the smears by direct examination but colonies exactly like those from the finger appeared on the cultures after 5 days.

The growths after several days were white and after about 1 week the growths especially on sugar mediums began to turn brown and soon became quite black. The surface became corrugated with rather deep irregular grooves and there was some growth into the depth of the medium. After numerous transfers on artificial mediums after a period of several months no important change has been noted. The strains still continue to produce a deep black pigment.

Microscopicaliy the growth consists of a dense feltwork of septate branching mycelial filaments with hyphae having many terminal and lateral spores more or less oval and pear-shaped. They are gram-positive and in every way correspond to the morphology of Sporotrichum schenckii. Chlamydospores in old cultures are found in moderate numbers.

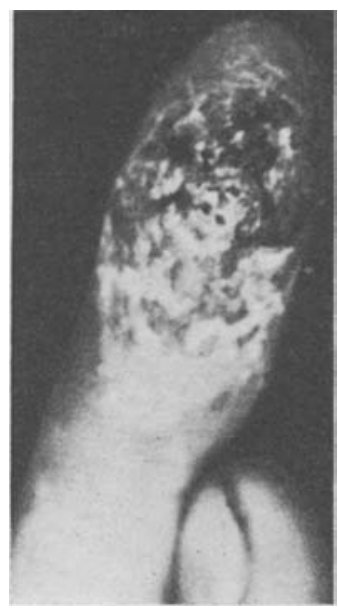

Fig, 1.-Initial lesion following a mouse bite on the finger.

White rats were inoculated with suspensions of the culture, some intraperitoneally, some subcutaneously. The former developed typical pearly gray nodules on the omentum and about the stomach, spleen and testicles. Two, after several weeks, showed nodular swelling on their hind legs and died. On necropsy the typical lesions of sporotrichosis of the long bones of the leg were found and cultures made from these bone lesions yielded pure growth of the sporotrichum. All the animals not treated with potassium iodid died after from 2-3 months.

The rats inoculated subcutaneously developed local lesions which later broke down forming ulcers from which the sporotrichum was repeatedly grown. Smears of the exudate from these lesions and also from the peritoneal nodules showed in abundance the characteristic elongated tissue forms. No branching or mycelial growths were found in the tissues. To several of the rats with lesions following the inoculations, potassium iodid was given subcutaneously in doses of $0.05 \mathrm{gm}$. The rats with cutaneous lesions responded promptly, the ulcers in the course of a few days showing marked improvement. A lesion, 
the size of a dime, on 1 animal, $j$ ust above the tail was entirely healed in about 3 weeks. Before this treatment was begun the lesions following subcutaneous inoculation of sporothrix had been steadily increasing in size,

When we first saw the patient the terminal phalanx of the left index finger was swollen, very firm and of a dusky red color. Two irregular shaped ulcers about $0.5 \mathrm{~cm}$. in length were present on the ventral surface from which a few small drops of thick yellowish pus could be expressed. These ulcers are shown in the accompanying photograph (Fig. 1). The first subcutaneous nodule about $0.5 \mathrm{~cm}$. in diameter was situated at the base of the index finger on its inner aspect. There were 15 others varying in size from $0.5-2 \mathrm{~cm}$. scattered along the course of the lymphatics on the back of the hand, the radial side of the forearm and the arm to about $5 \mathrm{~cm}$. below the axilla. Most of them were firm, painless, and with little or no discoloration over the surface. The largest nodule, located about $5 \mathrm{~cm}$. above the wrist was softer than the others and its surface was dark blue or violet in color. Softening was undoubtedly beginning in this lesion. From this nodule was aspirated the thick yellowish mucoid pus from which the pure cultures described were grown. The regional lymph glands were not enlarged. No other lesions were found at this time; a general examination showed the patient to be in all other respects a normal, well developed boy. His past and family histories, having no direct connection with the disease, are omitted.

Generally the patient feels quite well; his temperature for over 2 weeks has been normal; he has never had chills. The urine was normal. Leukocyte counts varied from 9,000-10,500; hemoglobin 90\%; erythrocytes 5,000,000; neutrophils, $65 \%$, small lymphocytes, $27 \%$, large lymphocytes, and transitionals $6.5 \%$, eosinophils $1 \%$, and basophils $0.5 \%$.

November 11, 15 grains of potassium iodid daily were administered and gradually increased to 30 grains a day. Within 10 days the ulcers were crusted over, no more pus was formed but the nodules appeared slightly larger and were all more or less discolored. November 23 , a bluish nodule $1 \mathrm{~cm}$. in diameter was found about $5 \mathrm{~cm}$. above the elbow on the inner surface of the right arm. This had probably been present for some time but had been overlooked. At this time the finger had almost regained its normal size and was healing rapidly. The nodules were decreasing in size. The treatment (30 grains of potassium iodid daily) was continued for 2 months at which time the finger was apparently healed; the nodules on the left arm had disappeared with the exception of a small one on the back of the hand, but the nodule on the right arm could still be palpated.

We did not see him again until February 24, when he presented the following condition. The end of the finger is swollen, the scar tissue is reddened with four small crusted areas scattered over it. A nodule about $1 \mathrm{~cm}$. in size has appeared on the calf of the left leg. The patient states that he discontinued the potassium iodid for 1 week after we last saw him (January 16) and that when he recommenced taking it he had such gastric distress that he stopped the medicine permanently. About a week ago the scar of the old ulcer broke open and some thick yellowish pus exuded. Since that time pus in small amounts has discharged from the finger each day. During this time he noticed new nodules appearing and the one on the hand growing larger.

He was immediately given 30 grains of potassium iodid daily. After 10 days the condition was again much improved. The nodule on the right arm became soft and on incising about 4 drops of a yellowish mucoid pus, similar to that obtained from the finger and the nodule on the other arm were expressed. Cultures and smears were made at once. No organism could be 
found in the latter but the former yielded pure growths of sporotricha after 5 days, demonstrating beyond question that this nodule was sporotrichotic. This lesion entirely healed in 2 weeks but remained somewhat discolored. With the continuance of the specific treatment all the lesions practically disappeared within 1 month.

We did not see the patient again until Aug. 23, 1917, when he presented himself with an open ulcer at the base of the index finger. He had discontinued potassium iodid some months previously. He stated that this "sore" had been discharging for about a month. A watery, yellow pus could be forced out but cultures made from this contained only staphylococci. No subcutaneous nodules were present and the patient felt in the best of health. October 10, the condition was the same but the cultures this time yielded not only staphylococci, but also a few colonies of sporotricha. Cultures October 23, also yielded Sporotrichum schenckii.

He now commenced with potassium iodid again and continued for 3 weeks. During the early part of this period the sinus was washed twice a week with tincture of iodin and with Lugol's solution. This caused profuse discharge which continued for a few days. The abscess closed but reopened the latter part of December when he recommenced taking potassium iodid. Cultures were made Jan. 15, 1918, but contained only staphylococci. There was no discharge from this date until February 23, when a few drops of pus were obtained, potassium iodid having been taken during the entire period. The abscess, which measured about $1.5 \mathrm{~cm}$. and was dusky red when first seen, measured about $1.8 \mathrm{~mm}$., was not discolored and had apparently a dense connective tissue wall. Roentgen-ray pictures in October demonstrated that the lesion was not associated with bone or joint involvement. At the present time there is a discharge of a drop or two of pus. every 2 nd day and the lesion is apparently slowly healing, due probably to the larger intake of potassium iodid which has been increased to 60 minims daily.

The symptoms presented here are typical of the disseminated subcutaneous gummatous type of sporotrichosis. They include the characteristics emphasized by Gougerot; numerous lesions beginning in the form of painless nodules with partial softening and without marked impairment of the general condition; mucoid or citron yellow pus; cold indolent swellings; no enlargement of the regional lymph glands. A point which he considers most characteristic, the formation of abscesses from the softened nodules with violet colored margins, did not appear. This may have been on account of the early diagnosis and recourse to iodid therapy.

An important point is the dissemination of the infection to various portions of the body as shown by the occurrence of nodules on the opposite arm and on the left leg. The probable routes of infection were the lymph or the blood stream. Blood cultures were sterile in this case, but it is known that the organisms appear in the blood stream at times in human sporotrichosis. In experimental sporotrichosis in rats positive cultures from the heart blood are readily obtained in advanced 


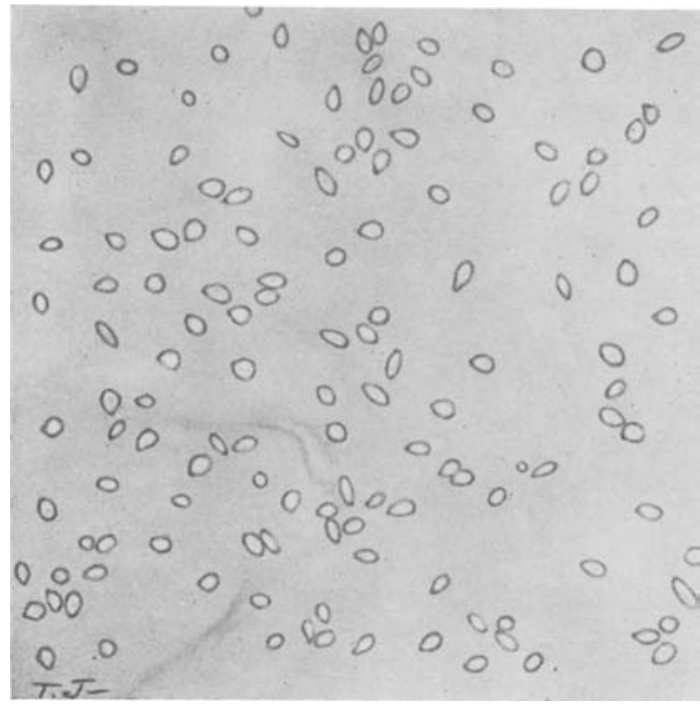

Fig. 2.-Sporo-agglutination. Control serum 1.40.

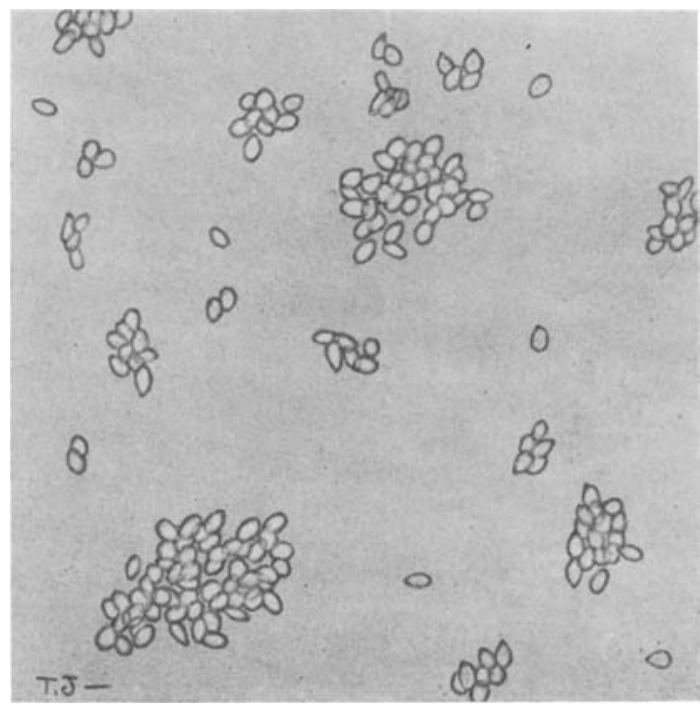

Fig. 3.-Sporo-agglutination. Patient's serum 1-40. 
stages of the infection. There were no demonstrable lesions of the internal organs at any time in this patient.

Potassium iodid in this case was quite specific for the disease and confirms previous observations that it is one of the best examples of a specific therapeutic agent known. However, as illustrated by the repeated recurrences in this case, the drug must be given in moderate or large doses consistently and for some time after all lesions and symptoms have disappeared.

From time to time the serum of the patient was tested for the presence of agglutinins. The homologous as well as French and American strains were used; also the original Schenck-Hektoen strain of Sporothrix schenckii. The technic was as follows:

The suspension was made by macerating in a mortar with salt solution some of the tough growth several weeks old from an agar slant and then straining it through either a coarse filter paper or a plug of cotton. The mycelial filaments are held back on the filter and a pure suspension of spores is obtained which may then be diluted to the proper degree. A suspension containing about $200-400$ spores in a high power field is a convenient one to use. A small amount of formalin added to the suspension will kill the organisms but does not interfere with the test.

The macroscopic test we have not found suitable since the large heavy spores soon settle out in both specific and normal serum suspensions. A convenient way to obtain a definite clumping is to make the various dilutions in small tubes and allow to stand for several hours or over night. The tubes are then shaken and hanging drop preparations made at once. The spores under the influence of the sertum soon begin to clump and the reaction is usually a very definite one. The final reading is taken after 24 hours. Figure 3 shows this phenomenon of spore agglutination microscopically. The results are tabulated in Table 1.

It will be noted that in the various tests agglutination appeared at fairly uniform dilutions, these being $1 / 160$ or occasionally $1 / 320$. Furthermore, the agglutination titer was practically uniform for the various strains, no appreciable differences being noted between the homologous strain, a strain obtained from France (Sporotrichum beurmanni) and the original Schenck-Hektoen strain. This is in accord with the results obtained by one of us, ${ }^{8}$ using immune rabbit serum. They also confirm the results of Wilder and $\mathrm{McCullough}{ }^{9}$ who tested variots strains of sporotricha with serum from a case of sporotrichosis of the eye acquired accidentally in the laboratory. Their highest titer was $1 / 64$.

Controls of blood from various diseases including syphilis and blastomycosis gave no clumping in $1 / 20$ dilutions.

s Davis, D. J.: Jour. Infect. Dis., 1913, 12, p. 140.

- Jour. An.Med, Assn., 1914, 62, p. 1156. 
The agglutination test was first made on November 15 approximately 2 months after the bite and about 1 month after the appearance of nodules. At this time it was distinctly positive. November 23 it was again distinctly positive and indeed at slightly higher dilutions than in the previous test. December 15 and also December 30, tests were made again with similar results. Following the recurrence in January and February an agglutination test was again made February 26 which gave a distinct reaction at 1/320. No further tests were made until August 10 at which time the test was nearly negative there being only a slight clumping at $1 / 20$. In the meantime the nodules had disappeared under proper therapy though there was still a small open ulcer at the base of the finger which, as stated, at this time yielded only staphylococci.

Later, however, when the iodid therapy was discontinued by the patient and the discharge from the finger increased, cultures made from the pus again yielded sporotricha. In all probability a few organisms had been present continuously but were not detected by the culture in August. The discharge continued from the finger and at the present time (March, 1918) still persists

TABLE 1

Sporo-Agglutination of Various Strains with Patient's Serum on November 23

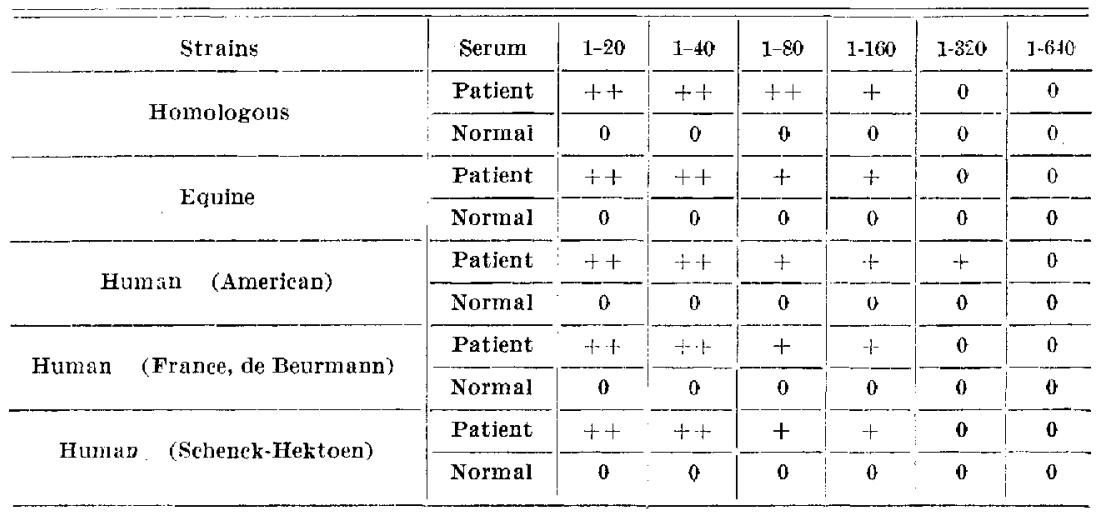

and cultures made from time to time have yielded sporotricha. Agglutination tests made Jan. 14, 1918, and Feb. 26, 1918, were again definitely positive at dilutions of $1 / 80$.

Complement fixation tests were made simultaneously with the agglutination tests. This infection has been noted by others to produce a high content of specific complement fixing substances.

The antigens for fixation were prepared in the same manner as for the agglutinins except that after filtering $0.5 \%$ phenol was added as a preservative. Four sporothrix strains were used in the tests, one from de Beurmann, the original Schenck-Hektoen strain, one isolated from a horse by Meyer, and the strain isolated from the patient. For control antigens we used one prepared in a similar manner from a strain of blastomycosis, three syphilitic antigens, and a gonococcus antigen. After suitable tests for anticomplementary action on the sporothrix and blastomyces antigens, one-third to one-thirtieth of the anticomplementary dose was used in the tests. Three-tenths $\mathrm{c} c$ of the equine, 
de Beurmann, and the patient's antigens, and $0.2 \mathrm{cc}$ of the Schenck-Hektoen antigen gave complete hemolysis. As small amounts as $0.01 \mathrm{cc}$ of the various antigens caused complete fixation when added to $0.1 \mathrm{cc}$ of the patient's serum. The chicken hemolytic system employing the technic previously described by one of us $^{10}$ was followed in all the tests. As control serum we used in every test a positive Wassermann serum, serum from several cases of blastomycosis and from various other diseases, and normal serum.

The patient's serum reacted specifically to the sporothrix antigens and was negative in all the control antigens during the first few months of the infection. Likewise the control serums gave complete hemolysis with the sporothrix antigens. Although it is a well known fact that a positive syphilitic serum will often give a nonspecific positive reaction

TABLE 2

Complement Fixation in Sporotrichosis with Various Antigens Dec. 12, 1916

\begin{tabular}{|c|c|c|c|}
\hline Antigen & $\mathrm{CC}$ & Serum & Result \\
\hline 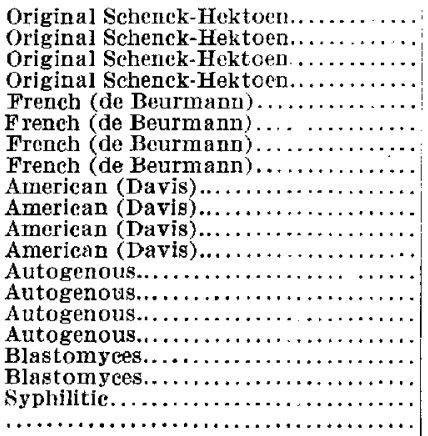 & $\begin{array}{l}0.01 \\
0.02 \\
0.1 \\
0.2 \\
0.01 \\
0.02 \\
0.1 \\
0.3 \\
0.01 \\
0.02 \\
0.1 \\
0.3 \\
0.01 \\
0.02 \\
0.1 \\
0.3 \\
0.2 \\
0.5 \\
0.1 \\
\cdots\end{array}$ & 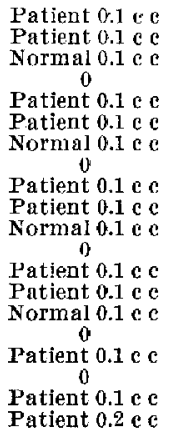 & $\begin{array}{l}\text { No hemolysis } \\
\text { No hemolysis } \\
\text { Complete hemolysis } \\
\text { Complete hemolysis } \\
\text { No hemolysis } \\
\text { No hemolysis } \\
\text { Complete hemolysis } \\
\text { Complete hemolysis } \\
\text { No hemolysis } \\
\text { No hemolysis } \\
\text { Complete hemolysis } \\
\text { Complete hemolysis } \\
\text { No hemolysis } \\
\text { No hemolysis } \\
\text { Complete hemolysis } \\
\text { Complete hemolysis } \\
\text { Complete hemolysis } \\
\text { Complete hemolysis } \\
\text { Complete hemolysis } \\
\text { Complete hemolysis }\end{array}$ \\
\hline
\end{tabular}

with bacterial antigens all the syphilitic serums tested were negative. The blastomycotic serums always resulted in complete hemolysis with all antigens including the blastomyces. This concurs with the work of B. Davis ${ }^{11}$ and others who were unable to demonstrate any specific: fixation substances for blastomycosis. The antigens and serums used, together with the results of a typical test, are presented in Table 2. Here approximately 200,000 spores sufficed to fix the complement with the antibodies in $0.1 \mathrm{c}$. of serum.

It was noted that the Schenck-Hektoen antigen possessed more anticomplementary substances than the other strains which naturally suggested a larger content of spores. Counts of the approximate number of spores in each

${ }^{10}$ Moore, J. J.: Jour, Infect. Dis., 1916, 18, p. 569.

11 Jour. Infect. Dis., 1911, 8, p. 190. 
antigen shortly after their preparation was as follows: de Beurmann 18 million, patient 21 million, Schenck-Hektoen 37 million per cm., thus confirming our supposition. It is an easy procedure to count the spores using the red field of a hemocytometer chamber and allowing 10-15 minutes for the spores to settle. This led us to believe that we might standardize a sporothrix antigen by estimating the number of spores in the solution. We therefore prepared an antigen by carefully touching a platinum loop to the surface of an old culture so as to get spores and but few mycelia and then transferring these spores to a small amount of normal salt solution containing $0.5 \%$ phenol. Such an antigen, containing 46 million spores per cc was tested with the SchenckHektoen antigen, then about 6 weeks old, and containing at that time approximately 500,000 spores per c c. The latter antigen, however, tested much stronger. Since the Schenck-Hektoen preparation undoubtedly contained some of the material from the macerated hyphae, nycelia and spores, and when first prepared contained less spores than the so-called spore antigen but reacted in smaller amounts when first prepared, it would appear that a crushed mixture would give the best antigen. The autolysis of the spores may increase the strength of the antigen as the antigenic property may be due to this factor. Further tests, however, did not confirm this.

A so-called spore antigen was carefully prepared as described and the same culture from the patient was ground up as a "triturated" antigen. They were diluted until each contained approximately the same number (30 million) of spores per cc. They were tested at once so as to give no opportunity for autolysis. Serums drawn at different times were used. The restlts indicate that there is little difference between the "spire" and "triturated" antigens; that approximately $2,000,000$ spores will fix the antibodies; that the antibodies will persist in the serum when sealed and on ice for a period of 6 months. We have lately tested serum 13 months old and find little apparent decrease in complement fixing substances. In addition we tested antigens of the various strains which had been kept for 9 months and although the spores had decreased from 19 to 25 million to $1,500,000$ and less per c c they still retained their antigenic value, indicating that the antigenic properties lie in substances which may act before or after the autolysis of the spore.

As the infection subsided under proper therapy there appeared to be a gradual decrease in the antibody content of the serum of the patient. Tests made with serum taken Dec. 30, 1916, did not show fixation of complement as strongly as with serum taken at earlier periods although all were tested at the same time with equal amounts of the antigens. After the recurrence in February, 1917, the reaction was as strong as before. In the following August, with none of the antigens could we demonstrate complement fixing bodies (Table 2), though the different sporothrix antigens were of nearly equal strengths, that is, contained approximately a like number of spores. From October, 1917, to March, 1918, the antibodies were found in as large amounts as in February, 1917.

When prepared by the same technic there was no apparent difference in the fixing ability of the various strains of sporotricha tested. 
Intradermal injections of $0.1 \mathrm{cc}$ of sporotrichin preparations of the de Beurmann and Schenck-Hektoen strains with control of a like amount of normal salt were made November 27 in the right arm. The sporotrichin was prepared like the agglutination suspensions, then sterilized in the autoclave for 1 hour and kept in the icebox. A normal individual was treated in the same manner as the patient.

After 48 hours the arm of the patient presented the following appearance: At the point of injection of the de Beurmann antigen was a small raised pustule about $5 \mathrm{~mm}$. in diameter, surrounded by an elevated, angry, indurated, hyperemic area about $1.4 \mathrm{~cm}$. in diameter which in turn was encompassed by an area of secondary hyperemia of lighter hue with an indistinct margin and which was about $5.5 \mathrm{~cm}$. in diameter. The appearance of the SchenckHektoen injection site was the same, the measurements being $1.4 \mathrm{~cm}$. for the primary hyperemia and $5 \mathrm{~cm}$. for the entire area. Surrounding the normal salt control was a reddened area $1.3 \mathrm{~cm}$. in diameter. The measurements of the areas on the arm of the normal individual were: de Beurmann $5 \mathrm{~mm}$., Schenck-Hektoen $5 \mathrm{~mm}$, normal salt $3 \mathrm{~mm}$.

During the first 24 hours after the tests, the patient complained of axillary tenderness but no enlarged glands could be palpated. After about 36 hours he was nauseated and had a headache. His temperature after 48 hours was $99.2 \mathrm{~F}$. The axillary glands were tender and slightly swollen. This was when the intracutaneous reactions were at their height. The erythema gradually disappeared, the skin became brownish in color and desquamated after several days. The arm of the patient regained its normal appearance after 7 weeks, the arm of the control in 3 weeks. March 7, 3 weeks after the recurrence a second test, using the de Beurmann sporotrichin, a blastomycin and normal salt in $0.1 \mathrm{cc}$ amounts, was made. Within 24 hours the patient complained of headache, malaise and nausea, and had axillary tenderness. Within 48 hours the sporotrichin test measured $7 \mathrm{~cm}$. $\times 7.5 \mathrm{~cm}$., with a central pustule $4 \mathrm{~mm}$. in size. The blastomycin test was $6 \mathrm{~mm}$, in diameter at its maximum and brownish red in color; the salt injection was $2 \mathrm{~mm}$. in diameter. The axillary lymph glands were palpable. A comparison of the reactions at their maximum is shown in Table 3.

Since it is now recognized that potassium iodid administered by mouth may increase the severity of certain intracutaneous tests, ${ }^{12}$ and as the control was not receiving potassium iodid, we decided to test several normal persons while they were taking this drug. The drug was administered by mouth in doses of 10 grains 3 times a day for several days. On the 7 th day the skin tests were made with equal amounts $(0.1 \mathrm{cc})$ of the same material and measurements made at the end of 48 hours. One control, a patient with blastomycosis, received intracutaneous injections of the de Beurmann and patient's sporotrichin when getting nothing. Later while taking potassium iodid he

12 Kolmer, Immermann, Matsunami and Montgomery: Jour. Lab. and Clin. Med., 1917, 21 , p. 401. 
was again tested with the de Beurmann strain and with a blastomycin prepared from his own organism. In one normal control the infections were made before and also while the person was receiving potassium iodid. In the others the first tests were made while receiving potassium iodid and repeated again 6 weeks after the drug had been discontinued. All these control intradermal tests yielded negative results (Table 3 ).

TABLE 3

The Influence of Potassiula Iodid on the Sporotrichin Intracutaneous Reaction

\begin{tabular}{|c|c|c|c|}
\hline \multirow{2}{*}{ Subject } & \multirow{2}{*}{ Antigens $0.1 \mathrm{e} e$} & \multicolumn{2}{|c|}{$\begin{array}{c}\text { Diameter in } \mathbf{M} \mathbf{M} \text { of } Z \mathrm{cone} \\
\text { of Reaction }\end{array}$} \\
\hline & & $\begin{array}{c}\text { Without } \\
\text { Potassium } \\
\text { Iodid }\end{array}$ & $\begin{array}{c}\text { Receiving } \\
\text { Potassium } \\
\text { Iodid }\end{array}$ \\
\hline 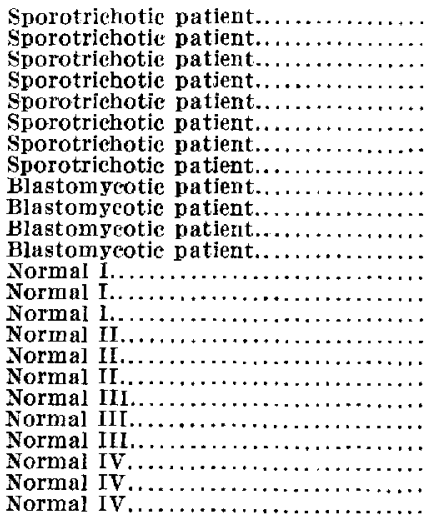 & 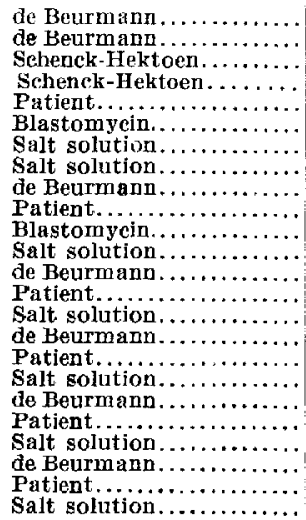 & $\begin{array}{l}55 \times 45 \\
\ldots \ldots \ldots \\
50 \times 43 \\
55 \times 45 \\
\ldots \ldots \ldots \\
\ldots \ldots \ldots \\
\ldots \ldots \ldots \\
5 \times 4 \\
7 \times 6 \\
3 \times 2 \\
5 \times 5 \\
5 \times 4 \\
2 \times 2 \\
\ldots \ldots \ldots \\
9 \times 8 \\
\ldots \ldots \ldots \\
11 \times \ldots \% \\
\ldots \ldots \ldots \\
10 \ldots \% \\
\ldots \ldots \ldots\end{array}$ & $\begin{aligned} & 55 \times 53 \\
& 75 \times 70 \\
& 52 \times 50 \\
& 30 \times 25 \\
& 33 \times 24 \\
& 8 \times 6 \\
& 12 \times 10 \\
& 4 \times 2 \\
& 9 \times 8 \\
& 9 \cdots 2 \\
& 9 \times 8 \\
& 1 \times 1 \\
& 9 \times 7 \\
& 9 \times 8 \\
& 3 \times 2 \\
& 6 \times 6 \\
& 12 \times 10 \\
& 2 \times 1 \\
& 6 \times 5 \\
& 6 \times 6 \\
& 2 \times 2 \\
& 5 \times 4 \\
& 6 \times 5 \\
& 1 \times 1\end{aligned}$ \\
\hline
\end{tabular}

As shown by this table the sporotrichin intradermal reaction is specific. It is not only greater in degree and severity, but it is accompanied by general symptoms of malaise and rise in temperature. There is apparently no difference in reaction between the de Beaurmann, the Schenck-Hektoen strains and the patient's strains. Blastomycin has no diagnostic value in blastomycosis and produces only a normal reaction in sporotrichosis. Potassium iodid does not interfere with the diagnostic value of sporotrichin.

In August, 1917, we had an opportunity of testing the patient at a time when he was not taking potassium iodid and had taken none for 4 months. It was at this time that he had a discharge from the base of the index finger from which only staphylococci were isolated. Of each of 3 sporotrichins, the de Beurmann strain, the Schenck-Hektoen strain, and the patient's strain, $0.1 \mathrm{cc}$ were injected. The measurements at the end of 48 hours were de 
Beurmann $5.5 \times 4.5 \mathrm{~cm}$., Schenck-Hektoen $5 \times 4.3 \mathrm{~cm}$., and patient $5.5 \times 4.5$ $\mathrm{cm}$. His temperature at the end of 24 hours was $99.4 \mathrm{~F}$. during which time he complained of headache and could not work. At this time complement fixation tests as stated above were negative. Agglutination tests made with different strains were likewise practically negative.

That the sporotrichum was causing the ulcer was confirmed by positive cultures obtained at later dates. These tests would suggest that the skin reaction is more delicate than the other tests. However, tests made in January, 1918, using as antigens the patient's and the Schenck-Hektoen strains, measured $2.5 \mathrm{~cm}$. $3 \mathrm{~cm}$. and $2.4 \times 3.3 \mathrm{~cm}$. The patient stated that with the exception of a headache he had none of the general symptoms produced by his former intracutaneous reactions. It is difficult to determine whether the antigenic property had been reduced in this time, as the antigens were the same as those used in all the previous allergic tests, or whether the reaction was decreasing. Supposing that this was not changed and finding as we did complement fixation and agglutinin bodies were high at this time it would appear that the immunity tests are not always parallel in a quantitative way. The findings of August, 1917, which were almost directly the contrary, would also suggest this.

\section{SUM MARY}

An instance of an infection with Sporotrichum schenckii following the bite of a field mouse in North Dakota is described. It is not known whether the organisms came from the mouse or from the soil or the skin.

The infection has now persisted for about 18 months, improving with administration of iodid and relapsing when the iodid is discontinued.

Repeated sporo-agglutination tests gave positive results at serum dilutions varying from 1-320 to 1-80. At one time, when the patient had almost recovered, the test was slight at $1-20$, but later became stronger. In general this test parallels the clinical course.

Complement fixation tests made at various times generally yielded definitely positive results, corresponding thus to the agglutination tests. In the icebox the antibodies in the serum retain their activity for over one year.

The antigens in these tests consisted of several strains of sporotricha including the autogenous organism, the original SchenckHektoen strain, a French strain (Sp. beurmanni) obtained from Gougerot, an equine strain from Meyer in the United States, and a 
strain previously isolated from a typical case in this country. All behaved approximately alike toward the patient's serum, pointing to the identity of the different strains.

Intracutaneous tests made with French and American strains on this patient yielded strongly positive reactions.

A blastomyces antigen did not cause a reaction in this patient nor did a blastomycotic patient react to the sporotrichum antigen.

The antigens are stable substances resisting heat and retaining their activity for over a year.

The administration of potassium iodid to sporotrichotic or normal persons does not appreciably alter the sporotrichin reaction.

In sporotrichum infections antibodies of various kinds are readily generated. This disease, therefore, is in marked contrast to blastomycosis, a closely related disease, in which antibodies are apparently generated with great difficulty or not at all. 
Fig. 1.-Cutaneous reactions on normal person, Upper, sporotrichin; lower, blastomycin; left, salt solution.

Fig. 2,-Cutaneous reactions on sporotrichosis patient. Upper, sporotrichin; lower, blastomycin; left, salt solution. 
Plate 4
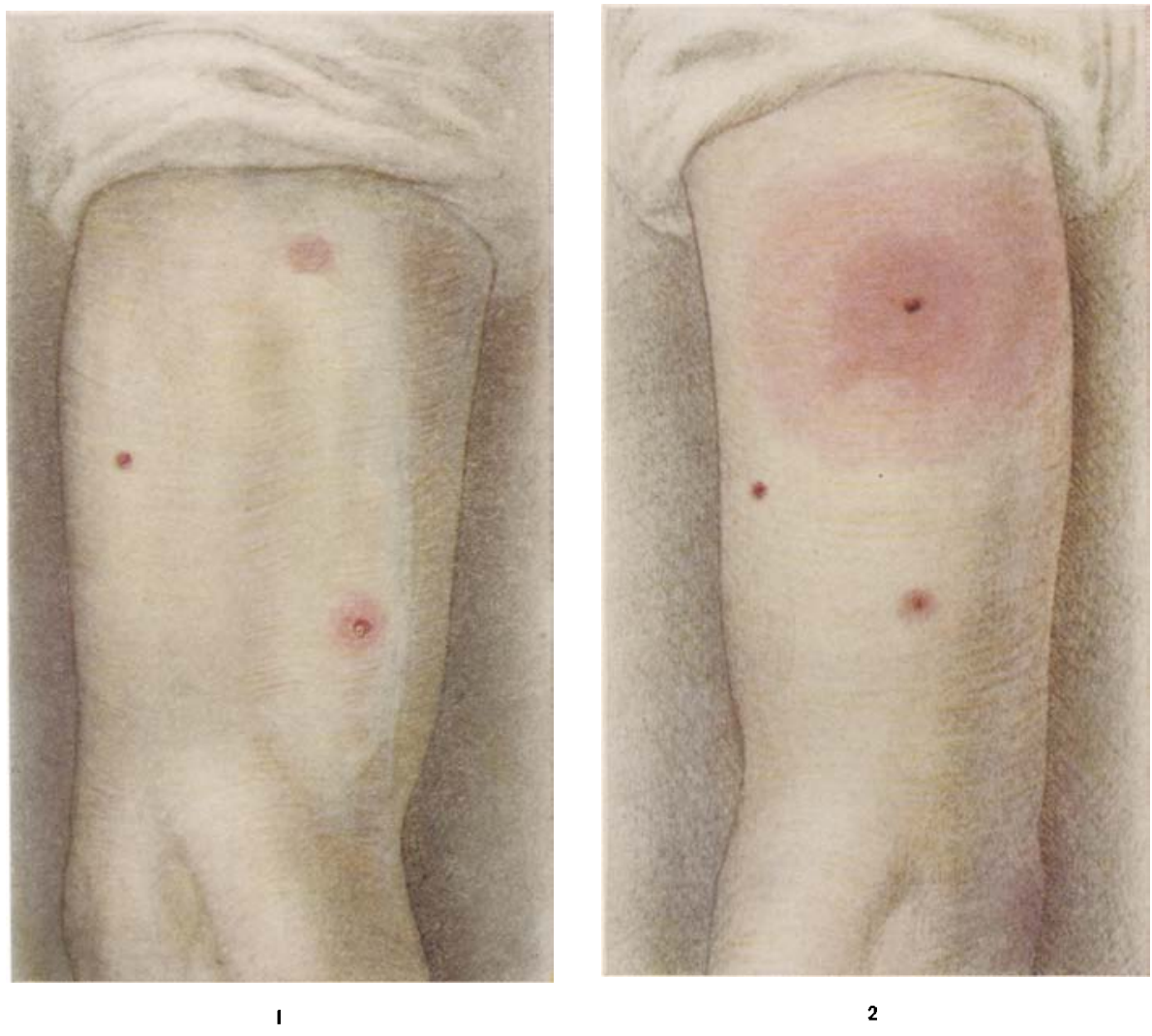

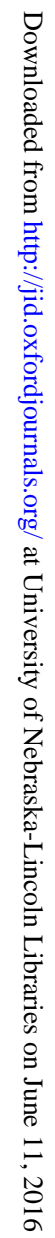

